\title{
INTRODUCCIÓN A LA BIOÉTICA
}

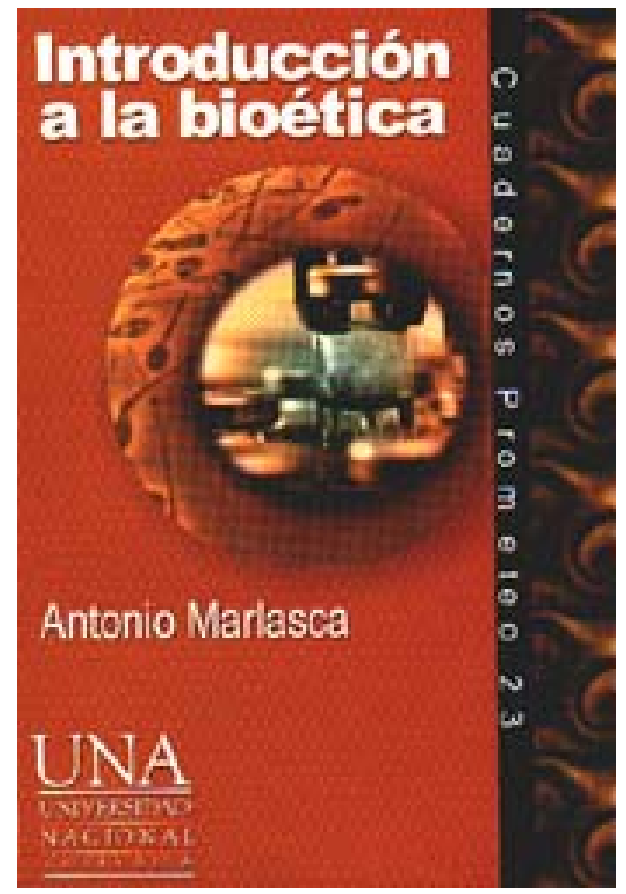

ANTONIO MARLASCA

ISBN 9968-26-007-X

Versión electrónica@ 2002 


\section{Tabla de contenido}

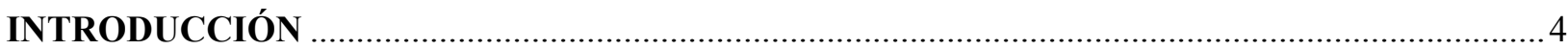

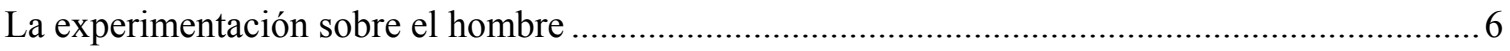

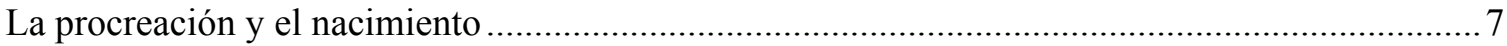

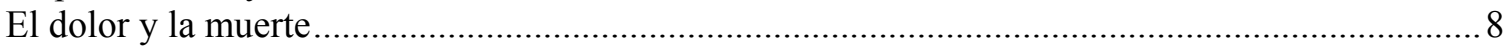

CAPÍTULO I

LA BIOÉTICA Y SUS PRINCIPIOS FUNDAMENTALES ............................................ 11

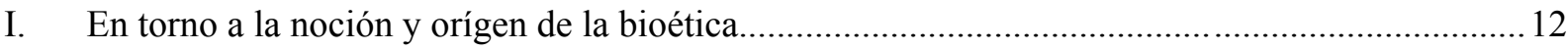

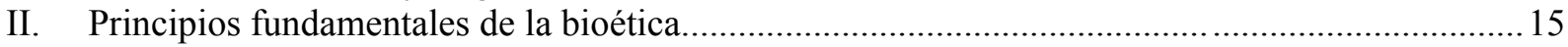

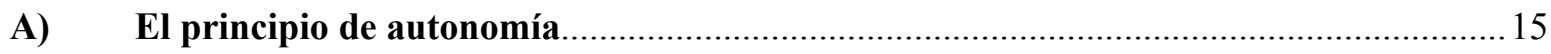

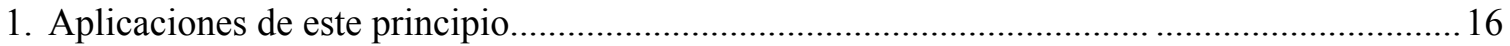

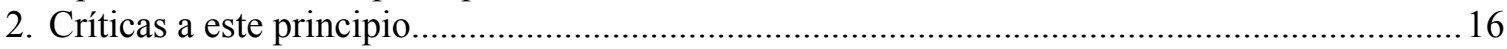

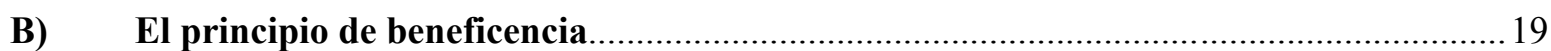

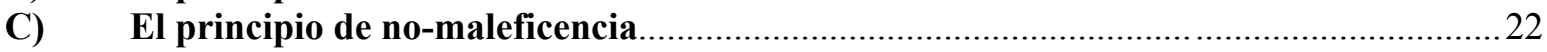

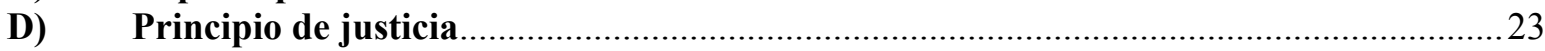

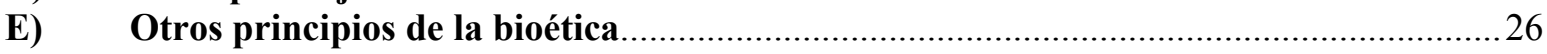

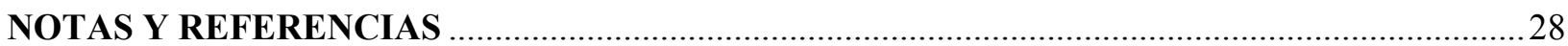




\section{Palabras de agradecimiento}

Quiero expresar aquí públicamente mi agradecimiento a algunas instituciones que tienen que ver directamente con la publicación de esta pequeña obra.

En primer lugar, a la Vicerrectoría de Investigación y a la Escuela de Filosofía de la Universidad de Costa Rica, que patrocinaron y financiaron el proyecto de investigación núm. 743-98-366 "Ética y tecnologías reproductivas de seres humanos" desde el 1 de junio de 1998 al 1 de junio del 2000.

En segundo lugar, al Instituto de Investigaciones Filosóficas de la Universidad de Costa Rica, que puso a mi disposición la estructura informática para que esta investigación pudiera concretarse y materializarse en un producto susceptible de ser publicado.

Por último -pero no lo último en importancia-- al Departamento de Filosofía de la Facultad de Filosofía y Letras de la Universidad Nacional (Heredia, Costa Rica), quien generosamente se ofreció a publicarlo en su prestigiosa, integradora y polifacética colección "Cuadernos Prometeo".

Muchas veces se ha pedido a las universidades públicas que trabajemos conjuntamente, apoyándonos e integrando nuestros esfuerzos y labores. Pues la publicación de esta obra es un ejemplo concreto, aunque modesto, de un trabajo en colaboración, olvidando viejos recelos y rivalidades, entre las universidades estatales.

El autor 
INTRODUCCIÓN 
La bioética es una disciplina relativamente reciente. Suele haber acuerdo al señalar su fecha simbólica-- de nacimiento: hacía 1970. Viene a ser una derivación de las éticas o deontologías profesionales, específicamente de la ética profesional médica, de cuño más o menos confesional o religioso. De ahí que en un primer momento tuvieron un papel destacado en su desarrollo teólogos moralistas y filósofos cristianos. Posteriormente se ubica en la perspectiva de una ética filosófica, racional -al menos, esa es su intención-- y va perdiendo importancia en ella el predominio teológico que acusó en sus inicios.

En la actualidad, aunque no es muy clara su ubicación en el conjunto de los saberes, la bioética se sitúa a caballo entre las ciencias y la filosofía e intenta fundamentarse en el contexto de una sociedad pluralista, secular y liberal y guiada por una racionalidad autónoma. El cualquier caso, la filosofía ha desempeñado y desempeña un papel primordial en la construcción de éste saber -la bioética-- que se quiere y profesa civil, secular, laico, plural e interdisciplinario, ya que, por una parte, permite un debate en profundidad de los grandes temas bioéticos y, por otra, abre ella misma la puerta al pluralismo ético en virtud precisamente de la pluralidad de concepciones filosóficas.

Si bien es cierto que la bioética ha adquirido ya mayoría de edad y se ha independizado de la tutela religiosa de las Iglesias, también es cierto que no existe una bioética secular absolutamente neutral. Cada autor, como era de esperar, habla y enfoca los temas bioéticos desde su propia tradición cultural. (Y no hará falta recordar que la religión forma parte de la cultura). En todo caso, en el seno de las sociedades laicas, pluralistas y permisivas, las intervenciones, a veces autoritarias y dogmáticas de la jerarquía de la Iglesia Católica en este campo, son percibidas como un intento de imponer en una sociedad plural las convicciones particulares de un grupo religioso (aunque sea muy numeroso). En el contexto actual de la bioética, la teología moral será bienvenida si acude con mentalidad dialogante y no de juez de lo permitido y lo prohibido, si se muestra más bien como suscitadora de valores que como determinadora de normas. En otras palabras, hoy sobra una teología moral de recetas prefabricadas y se echa de menos una teología discente, dialogante: una teología de propuestas más que de respuestas.

En concreto, los grandes temas y los grandes debates de la bioética son producto y consecuencia de la llamada "revolución biológica". Dicha revolución comienza con el descubrimiento de la estructura del ADN por Crick y Watson en 1953. De ahí arrancan una serie de intervenciones espectaculares sobre la vida, específicamente sobre la vida humana, y desde el principio aparecen también diversas orientaciones éticas.

Para unos, como R. Potter, inventor del neologismo bioética, la tarea del hombre de cara a la naturaleza se encuentra orientada e indicada por su conocimiento de los secretos de la vida, y de su continuidad y evolución. Una tarea eminentemente personal e insustituible, activa y beligerante, para salvaguardar la vida en su conjunto, acompañada en este caso por una visión mística de la evolución, inspirada en Teilhard de Chardin.

Para otros, como E. O. Wilson, el inspirador de la sociobiología, la ética viene ya inscrita en los genes. No se trata de que la cultura no juegue ningún papel en la elaboración de la ética , sino que el fundamento de ésta viene inscrito en el patrimonio genético, de tal manera que el fin 
último al que se ordena, aunque sea inconscientemente, no es otro que la conservación y la trasmisión de los genes - siempre egoístas--. Como el mismo Wilson propone, hay que convertir a los biólogos en los nuevos maestros de la educación ética: "Científicos y humanistas deberían considerar conjuntamente la posibilidad de que ha llegado el momento de retirar temporalmente la ética de manos de los filósofos y biologizarla".

En lo que sigue vamos a recordar algunos hitos, eventos y descubrimientos que, desde diferentes perspectivas, contribuyeron al nacimiento y espectacular desarrollo que ha conocido la bioética en las décadas pasadas.

\section{La experimentación sobre el hombre}

En la reconstitución de la prehistoria de la bioética hay que señalar la crueldad de la vivisección humana practicada sobre los condenados, que se remonta a la antigüedad, y el hecho de que el siglo XIX conoció lamentables infecciones debidas a experimentos, en particular relacionados con investigaciones sobre la sífilis.

Un punto culminante de esta triste historia lo constituyen el proceso de Nuremberg, que reveló las atrocidades cometidas por los nazis sobre sus prisioneros en los campos de concentración, y el subsecuente Código de Nuremberg (1947), que sentó las bases éticas para toda futura experimentación humana.

A pesar de esta normativa, posteriormente se descubrieron una serie de abusos en la muy reglamentada medicina de los Estados Unidos, que constituían, sin duda, flagrantes violaciones a la libertad y seguridad de los pacientes: inyección de células cancerosas a ancianos (1962), experimentación (para efectos de comparación) con grupos sifilíticos, algunos tratados con las medicinas adecuadas; otros, sin saberlo ellos, sin recibir ningún tratamiento adecuado (19721973). En ambos casos seres humanos fueron tratados como simples objetos de experimentación. Desde entonces la experimentación sobre humanos es un tópico ineludible en el debate bioético contemporáneo. Así fueron naciendo en diversas latitudes las Comisiones de Ética de la Investigación, en contraposición a las Comisiones de Ética de los Hospitales, cuya importancia y funciones van aumentando día tras día.

Concretamente el llamado Informe Belmont (de Estados Unidos, 1974) proponía los principios que deben guiar la experimentación con seres humanos. Entre otros, los siguientes:

- $\quad$ El respeto a las personas, que deben ser tratadas como agentes autónomos y no como simples objetos. Ello supone el consentimiento informado del paciente e incluso la posibilidad para éste de retirarse de la investigación en cualquier momento.

- La beneficencia que comprende un aspecto positivo: maximizar los beneficios para eventuales terceras personas, y un aspecto negativo, la no-maleficencia, es decir, no dañar a nadie.

- La equidad: mientras que en el pasado las experimentaciones y las investigaciones recaían casi siempre sobre los pacientes más pobres de los hospitales, en el futuro habrá que tomar medidas oportunas para evitar que se repitan esas situaciones francamente discriminatorias. 


\section{La procreación y el nacimiento}

El desarrollo, en torno a los años 1970, de las técnicas de diagnóstico prenatal de malformaciones congénitas llevó en muchos casos a situaciones trágicas, a verdaderos dilemas, que conmovieron la opinión pública. En efecto, en muy pocos casos las enfermedades detectadas por un diagnóstico prenatal se pueden curar. En la mayoría de los casos, cuando el diagnóstico prenatal descubría malformaciones graves en el feto, tal diagnóstico equivalía prácticamente a una sentencia de muerte para el mismo. Se cura la malformación suprimiendo al sujeto de tal anomalía. Se replica que, en este caso, el enfermo no es el feto o el bebé, sino el conjunto familiar constituido por el bebé, los padres, eventualmente los hermanos, y es a este conjunto a quien se quiere preservar de un mal.

El problema, si cabe, se agudiza en los recién nacidos afectados con una malformación grave. La eventual voluntad de los padres de no "salvar" a tales bebés junto a la prohibición formal del infanticidio desemboca en dilemas insuperables "resueltos" a veces con la práctica de "dejar morir".

Obviamente, en estos y parecidos casos se plantea el problema del status (antropológico y jurídico) del feto y del bebé. El reconocimiento general, en casi todos los países, del bebé como una persona con plenos derechos, orienta hacia la eutanasia pasiva la "solución" de los casos difíciles; mientras que el status reconocido al embrión o al feto da lugar a una escala de posiciones desde considerarlo como un simple "órgano" de la madre, hasta reconocerlo como una "persona", con todos sus derechos desde la concepción, pasando por la postura intermedia de verlo como un "ser humano potencial", que permite, al menos en principio, la continuación del diálogo entre las dos posturas extremas recién aludidas.

Otro tipo diferente de problemas éticos se plantean con el recurso a los medios artificiales de procreación. Entre los numerables temas que se abordan dentro de la bioética, éste de la reproducción asistida - conjuntamente en los últimos años con el de la clonación-- es el que más ha llamado la atención en casi todos los países en las últimas décadas. Aquí se mezclan los problemas de la fecundación in vitro para parejas casadas con otras situaciones que implican el recurso a madres sustitutas (o madres de alquiler). En realidad estamos ante problemas diferentes: los que, en la mayor parte de los casos, no cuestionan ni atentan contra la estructura tradicional de la familia y de la filiación (fecundación in vitro dentro de la vida de una pareja), y los que rompen con las formas tradicionales de filiación (técnicas que suponen el recurso a madres de alquiler).

Todas éstas cuestiones han suscitado grandes controversias y a veces enconadas polémicas en los países con gobiernos liberales y democráticos. Y ello debido a dos razones principales. Por un lado, tales debates eran la continuación a otro nivel de los que anteriormente habían tenido lugar en torno a los métodos anticonceptivos y al aborto y que, en el fondo, eran la expresión de reivindicaciones radicales femeninas sobre el papel y la condición de las mujeres en una sociedad laica, pluralista y democrática. Por otro lado, al abordar los diversos problemas relacionados con la fecundación y el comienzo de la vida, se tiene la impresión de que se está rompiendo un tabú y se está atentando contra algo sagrado: la identidad humana, la forma de perpetuarse la especie, algo a lo que siempre se había otorgado un carácter sacral. 


\section{El dolor y la muerte}

Los desarrollos o progresos de la medicina -- según como se mire-- en los últimos años han desembocado, a veces, en la prolongación de una "vida artificial" para muchos enfermos: se les alimenta por vía intravenosa, se les hace respirar con un aparato eléctrico, se les estimula el corazón cuando éste quiere detenerse, etc. El caso extremo se presenta con enfermos en coma irreversible y con una vida puramente vegetativa. ¿Cuándo hay que desconectar los aparatos? ¿Cuándo puede decirse de un enfermo en coma que está todavía vivo? Se ha llegado a elaborar una nueva concepción de la muerte: muerte cerebral. Y a los enfermos que sufren intensamente sin ninguna esperanza de recuperación ¿hay que dejarlos morir en una situación desesperada? Reaparece así el tremendo problema de la eutanasia con todos sus equívocos y ambigüedades. Desde otro punto de vista, el llamado "encarnizamiento terapéutico" es otra consecuencia inesperada de los "avances” en tecnologías médicas. ¿Hasta dónde hay que llevar la lucha por la vida? ¿Cuándo hay que tener el coraje de aceptar el "fracaso" y definitivamente "tirar la toalla"? Actualmente en algunas ocasiones se usa y abusa de terapias cuyos resultados son terriblemente inciertos. Por ejemplo, los efectos de la quimioterapia anticancerosa son con demasiada frecuencia aleatorios y su eventual eficacia terapéutica se obtiene al precio de una elevada toxicidad.

Por otro lado, la preocupación por el dolor va llenando un espacio cada vez mayor en la ética médica. Hasta el punto que algunos piensan que la lucha contra el dolor, en un futuro no muy lejano, vendrá a desplazar a la lucha contra la muerte, como el primer objetivo de la medicina. En cualquier caso, el dolor también se ha convertido en objeto directo de terapias específicas a través de la aparición de "clínicas del dolor".

$* * *$

Estos son algunos de los temas que han ido apareciendo o reapareciendo en el panorama variopinto y heterogéneo de la bioética. Por supuesto que no los hemos mencionado a todos: en los últimos años ocupan las primeras páginas de los medios de comunicación los problemas referentes a terapias genéticas, las posibles aplicaciones del proyecto "genoma humano", las eventuales modificaciones del patrimonio genético de la humanidad, la oportunidad de la clonación de seres humanos, las aplicaciones terapéuticas de la clonación de células embrionarias, etc.

A través de éstos tópicos tan diversos entre sí, en todos ellos la bioética se encuentra siempre ante un dilema: ¿son legítimas o ilegítimas las prácticas y las técnicas que se utilizan? Aunque parezca paradójico, los que trabajan en este vasto campo -interdisciplinario-- de la bioética quieren que haya algunas reglas, pero no una reglamentación detallista, quieren pautas morales, pero no normas jurídicas. La bioética aspira a realizar su función en un clima de libertad, de negociación, de compromiso, de acuerdos y consensos, aunque sean parciales y provisionales.

Desde el punto de vista propiamente ético, algunos principios parecen adquirir una importancia cada vez mayor. El primero, sin duda, es el ya formulado hace tiempo por Kant, a tenor del cual nunca se puede tratar a un ser humano como simple medio u objeto. De ahí la 
relevancia dada al "consentimiento informado" y a la autonomía del paciente. El segundo principio tiene que ver con el carácter cada vez más secular, laico y pluralista de nuestras sociedades. Es un hecho que todo lo que se refiere a la legitimidad de las intervenciones sobre la procreación, sobre la vida y la muerte del ser humano, se encuentra con convicciones y reacciones diferentes en nuestras sociedades. La cuestión fundamental en tal contexto - con un grado de dificultad no inferior a la de hallar la cuadratura del círculo-- consiste en proponer máximas y principios prácticos de acción que, siendo comunes y aceptados por todos, respeten al mismo tiempo la diversidad de esas convicciones y creencias. De ahí la importancia dada al intercambio de pareceres, al diálogo, a las negociaciones, a las transacciones y a los acuerdos operativos, aunque sean provisionales y parciales.

En las páginas que siguen van a examinarse desde el punto de vista ético algunos de los múltiples temas y problemas que acabamos de mencionar. No hemos tenido otra opción que hacer una selección de los mismos. No obstante, creemos que hemos escogido los tópicos más importantes y más debatidos actualmente dentro de la bioética.

Concretamente en el primer capítulo se expone el origen y la noción de bioética y se analizan críticamente los cuatro principios fundamentales, ya clásicos, de la bioética. El capítulo segundo aborda una cuestión permanente y siempre actual, posiblemente la más difícil y polémica de la bioética: el estatuto antropológico del embrión y las principales teorías al respecto. Indudablemente el eventual lector se ubicará a priori en alguna de las tres posiciones reseñadas. El capítulo tercero estudia una serie de fenómenos recientes relacionados con las tecnologías reproductivas de seres humanos: inseminación artificial, fecundación in vitro en sus diversas modalidades, recurso a la maternidad subrogada, posibilidad de la clonación humana, etc. El capítulo cuarto va dedicado al examen de la eugenesia y sus promesas incumplidas, a los problemas ligados a la esterilización, a los avances de la moderna genética y sus posibles aplicaciones terapéuticas y a las perspectivas abiertas con la finalización del "proyecto genoma humano". El capítulo quinto se enfrenta a los temas inevitables que tienen que ver con el ocaso y finitud de toda vida humana: el dolor, la muerte y su posible definición o delimitación, la eutanasia en sus diversas modalidades, el testamento vital, etc. Finalmente en un "epílogo para costarricenses" se someten a examen y juicio crítico algunos de los temas bioéticos discutidos, por diversos motivos, en el seno de la sociedad costarricense en los últimos años: el estatuto jurídico del embrión, el vacío legal sobre técnicas de reproducción asistida, el reciente decreto sobre esterilización voluntaria y el derecho a una muerte sin dolor. Tópicos, todos ellos, a no dudarlo, de una importancia capital y de una innegable actualidad.

Un problema grave dentro de un tratado de bioética es ciertamente el del aborto. Consciente y voluntariamente lo hemos eludido y silenciado en este ensayo. Las razones son varias. En primer lugar, porque el tema del aborto en los últimos años ha sufrido una disminución en la literatura ético-médico-jurídica debido a que ha sido despenalizado en casi todos los países occidentales. En segundo lugar, porque difícilmente podríamos añadir algo novedoso y de peso a lo mucho ya dicho en torno a este tópico, sea para defender su eventual despenalización, sea para estigmatizarlo como inmoral. En tercer lugar - y esto tiene que ver más con nuestro contexto cultural y social-- porque parece un hecho evidente que la mayoría de 
la sociedad costarricense está muy conforme con la normativa legal, moral y religiosa actuales que rechazan de plano el aborto. Nos pareció, pues, innecesario y ocioso reexaminar o cuestionar algo que la mayoría considera obvio e indiscutible: la sacralidad de la vida humana desde sus inicios. De todas formas, y aunque sea en forma indirecta, lo que exponemos en el capítulo segundo en torno al "estatuto antropológico del embrión" sin duda alguna tiene mucho que ver y puede relacionarse sin dificultad con el sempiterno problema del aborto.

Los diversos temas que van apareciendo en el presente ensayo son analizados y enfocados - al menos esa es nuestra intención - desde una óptica exclusivamente racional, filosófica -si se nos permite utilizar una palabra tan devaluada-- laica y secular. Es decir, se ponen entre paréntesis las posibles creencias o convicciones religiosas. Claro que el autor no ignora que su "razón" es también un producto cultural historizado y resultado de una educación y socialización a las que nadie - por muchos esfuerzos que se hagan-- puede sustraerse. Por ello, no pretende dogmatizar ni pontificar. Su "razón" es una más en el concierto polifónico de múltiples voces, razones y racionalidades. Por lo mismo, también está lejos de su propósito intentar convencer al eventual lector para que piense exactamente como él. Las páginas que siguen quieren ser, más bien, una invitación al diálogo y al intercambio de pareceres y de opiniones con cualquier lector de buena voluntad, abierto tanto a un posible consenso como a un eventual disenso.

Una última acotación. En casi todos los capítulos se tiene muy en cuenta y se expone profusamente la doctrina de la Iglesia Católica sobre los diversos temas que se estudian. Ello obedece también a una razón de tipo cultural y social: al enorme e indiscutible peso que tiene la posición de esta Iglesia sobre estos tópicos en nuestras sociedades latinoamericanas mayoritariamente católicas. 


\section{CAPÍTULO I}

\section{LA BIOÉTICA Y SUS PRINCIPIOS FUNDAMENTALES}




\section{En torno a la noción y orígen de la bioética}

En las últimas décadas ha surgido con un ímpetu y una fuerza extraordinarios un nuevo saber: la bioética. A nivel epistemológico se discute si efectivamente la bioética es una ciencia novedosa o si, más modestamente, no es sino una aplicación de la vieja ética --o, si se prefiere, de la ética médica-- a nuevos problemas y situaciones que han ido apareciendo con los adelantos tecnológicos. En cualquier caso, la terminología que se utiliza es relativamente novedosa --para comenzar bioética es un neologismo acuñado recientemente a partir de los vocablos griegos bios y ethos, que vendría a significar algo así como ética de la vida-- y se ha extendido desde 1970, partiendo de Estados Unidos, su lugar de origen, como una inmensa mancha de aceite por toda la faz de la Tierra.

Al margen de las discusiones académicas y un tanto bizantinas --sobre si es o no una nueva ciencia-- la bioética puede definirse de la manera siguiente: "es el estudio sistemático de la conducta humana en el área de las ciencias de la vida y del cuidado de la salud, en cuanto que dicha conducta es examinada a la luz de los valores y de los principios morales" (1).

Como puede verse el objeto de este nuevo saber es amplísimo: la conducta humana en todo lo que tiene que ver con la vida y con la salud. Es decir, en el objeto de estudio de la bioética quedarían comprendidas la ética, la deontología médica, la biología, la medicina, la antropología, la sociología, la ecología o ética ambiental, etc.

Tratando de ser más concretos podemos dar la siguiente lista --si no exhaustiva, por lo menos bastante completa-- de los temas que se estudian y discuten actualmente en la bioética:

1) Tópicos que tienen que ver con la reproducción humana: control de la natalidad, aborto, inseminación artificial, fecundación in vitro, manipulación de gametos y embriones, maternidad subrogada, clonación, diagnóstico prenatal, consultas genéticas, terapia génica, eugenesia y esterilización.

2) Intervenciones en el patrimonio genético: manipulación de $\mathrm{ADN}$ tanto humano como no humano; proyecto genoma humano que concluirá próximamente.

3) Intervenciones que tienen que ver con el fin de la vida humana: atención y cuidados de los enfermos terminales, obstinación terapéutica, eutanasia en sus diversas modalidades, suicidio asistido, etc.

4) Manipulación del cuerpo humano y de sus órganos: transplante de órganos, injertos y prótesis.

5) Manipulación de la conducta y de la personalidad: neurocirugía, modificaciones de la conducta por medios eléctricos, químicos, psicotrópicos, etc.

6) Manipulación de seres y medios vivos no humanos: plantas y alimentos transgénicos, experimentos con animales, armas biológicas, etc.

7) Experimentación con seres humanos y con sus elementos germinales: gametos y embriones humanos.

8) Problemas ocasionados por las modernas tecnologías en nuestro habitat natural: ecología y ética ambiental, sobrepoblación humana, destrucción de ciertas especies, etc. 
9) Problemas que tienen que ver con la justa y equitativa distribución de los recursos sanitarios: tales recursos son siempre escasos en el amplio campo de la salud socio-comunitaria, frente a las necesidades siempre crecientes y cada día más difíciles de satisfacer, incluso desde el punto de vista meramente económico. Estos problemas habría que analizarlos dentro del llamado "principio de justicia".

Como se ve es amplísimo el espectro de los tópicos que se abordan en la bioética: todos los que de alguna manera tienen que ver con la vida humana $\mathrm{y}$, especialmente, con su inicio $\mathrm{y}$ con su fin.

Los factores que de diversas maneras, han intervenido en la génesis de la bioética van desde los progresos científicos - tecnológicos en diversos ámbitos (ingeniería genética, tecnologías reproductivas de seres humanos) pasando por un nuevo concepto de salud y calidad de vida (autonomía del enfermo, derechos del paciente, salud reproductiva, etc.) hasta una nueva concepción de la ética que ha pasado de ser una moral fundamentada en creencias religiosas, códigos deontológicos y supuestos metafísicos hasta configurarse --o al menos intentarlo-- como un saber estrictamente racional, laico, secular, democrático (en cuanto resultado de acuerdos mayoritarios y decisiones racionales) que puede ser compartido, en principio, por cualquier persona de cualquier religión o ideología. Sobre este último aspecto de capital importancia, volveremos a hablar más adelante al tratar de la metodología --interdisciplinaria-- de la bioética. Sin embargo conviene que desde ahora vayamos aclarando conceptos y posiciones.

Lógicamente la parte más polémica y problemática de la definición arriba transcrita de la bioética es la que afirma que la conducta humana es "examinada a la luz de los valores y de los principios morales". La pregunta obligada es obviamente ¿cuáles son esos valores y esos principios morales? ¿Hay acaso unos valores y unos principios morales compartidos por todos los seres humanos? La respuesta a este último interrogante es --tiene que ser-- forzosamente negativa, como por desgracia nos lo atestigua la experiencia diaria de luchas cruentas por diferencias culturales, religiosas, ideológicas, nacionales, étnicas, etc. Y naturalmente aquí comienzan ya los problemas más serios de la bioética: ¿a qué valores y principios acudir para basar en ellos las decisiones a tomar y la conducta a seguir?

Hasta ahora las éticas que han aparecido si bien la mayoría de ellas aspiraban a la universalidad --es decir, a ser válidas para todos los seres humanos-- en realidad su validez quedaba y queda circunscrita al ámbito cultural dentro del cual han sido concebidas. De tal manera que la ética como un saber normativo aceptado por todos los seres humanos hoy por hoy no deja de ser un desideratum y una aspiración (2).

Más en concreto, los tratados de ética aunque se digan elaborados con bases estricta y exclusivamente racionales, en el fondo la mayoría de ellos remiten más o menos subrepticiamente a fundamentos religiosos. De tal manera que en la práctica las éticas difieren profundamente según que sus autores sean creyentes o no; y en el primer caso se distinguirán también según el autor sea musulmán, taoista, judío, católico, calvinista, etc.

Frente a esta realidad tan variopinta, dispar y contradictoria, la bioética, si aspira --como en verdad lo intenta-- a la universalidad, tendrá que partir de otros presupuestos. Presupuestos o principios que no sean propios y exclusivos de una cultura, de una religión, de una nación, de 
una ideología política, de una etnia, etc. Presupuestos que en teoría, podrían aceptar los protestantes, los musulmanes, los ateos, los católicos, los deistas, los agnósticos, los judíos, los comunistas, los masones, los budistas, los animistas, etc. ¿Será esto posible? La cuestión, como se ve, no es baladí, sino que tiene una importancia capital.

Para comenzar está claro que la ética debiera "desconfesionalizarse", es decir, deberá abandonar --o si se prefiere, poner entre paréntesis-- su fundamentación religiosa, bien sea explícita o bien sea implícita. En otras palabras, habrá que partir de una ética secular, profana, y basarse en la sola racionalidad humana --compartida en principio por todos los seres humanos, aunque después en la práctica haya muchas formas de entender y llevar a la práctica esa "racionalidad"-- buscando unos principios orientadores que se ubiquen "más allá del ordenamiento jurídico y deontológico y más acá de las convicciones religiosas" (3). Sin embargo, conviene añadir que aunque sería deseable que todas las propuestas, principios y normas asumidas por la bioética estuviesen siempre fundamentadas en la sola racionalidad humana, ello no siempre será posible (porque la razón humana también está interpretada, culturizada, historizada, en algunos casos "ideologizada", etc. hasta el punto que lo que para algunos grupos es racional, para otros no lo es), de tal manera que en la práctica, y en algunos casos, habrá que recurrir a la transacción, a la negociación, a acuerdos parciales, a consensos mayoritarios, etc.

En este sentido la bioética tiende a convertirse en un foro de debates y de decisiones compartidas y consensuales, en un contexto social e ideológico plural y secular, en el que ningún grupo cultural tiene a priori la última palabra, la solución definitiva, y en el que todos los participantes pueden aportar elementos y hacer propuestas racionales hasta llegar a una ética de mínimos, o a decisiones, aunque sean muy elementales, compartidas por todos, o al menos por la mayoría. Así, dentro de la bioética es imprescindible un talante democrático, negociador, en busca de consensos compartidos, pues si algo ha puesto de manifiesto la bioética ha sido precisamente "la multiplicidad irreductible de nuestras sociedades y, a contrario, el carácter dogmático, totalitario $\mathrm{y}$, por lo tanto intolerable de toda voluntad no pacífica de dar a las preguntas bioéticas respuestas con pretensión universal, ancladas en principios y fundamentos absolutos que se impongan por ser las únicas verdades" (4).

El punto de partida de la bioética es, pues, un hecho innegable: la existencia del pluralismo moral en nuestro mundo globalizado, pluralismo hoy más evidente que nunca. Por supuesto, no se trata de sostener que ese pluralismo o esa diversidad moral sea un bien en sí mismo, ni tampoco de celebrar el caos. Se trata, más bien, de no negar los hechos, sino partir precisamente de ellos.

No obstante, a pesar de ese pluralismo moral vigente en la actualidad, se han elaborado, y casi aceptado universalmente, algunos principios fundamentales, que están a la base de la bioética --que constituyen sus fundamentos-- y que pasamos a analizar a continuación con algún detalle. 


\section{Principios fundamentales de la bioética}

Advertimos que los autores que tratan esta temática no concuerdan ni en el números de principios que reseñan ni en el orden de importancia de los mismos. Por nuestra parte, haremos una exposición sintética y crítica de tales principios, ateniéndonos a criterios de orden lógico y claridad pedagógica-- tal como nosotros los entendemos-- sin sujetarnos a ningún autor en particular. No obstante, dado que la bioética nació, como queda dicho, en Estados Unidos, y ahí se publicaron las obras pioneras sobre esta materia, prestaremos particular atención a algunas de estas obras que han marcado la pauta, y en especial a la voluminosa y ya clásica Fundamentos de la Bioética de H. Tristram Engelhardt.

\section{A) El principio de autonomía}

Este principio recibe otras denominaciones como, por ejemplo, principio de permiso o principio de autoridad moral. Autonomía significa darse leyes (nomoi) a sí mismo (autos), imperio sobre sí mismo, gobierno propio, o autodeterminación. Básicamente este principio afirma que todo ser humano es un agente moral libre, y, como tal, debe ser respetado por todos, incluso y especialmente por aquellos que no comparten sus posiciones morales. De acuerdo a este principio no se puede, bajo ninguna circunstancia, hacer uso de la violencia o de la fuerza en cualquiera de sus formas (física, psicológica, moral) sobre un ser pacífico dotado de consciencia, razón y libertad. Ninguna fuerza puede ser impuesta a quien no la haya consentida previa y libremente. Hay que rechazar, pues, toda presión o violencia para obligar a las personas a aceptar un determinado valor o punto de vista que no comparte y que se las quiere imponer. Este principio es, según uno de los principales autores de bioética (5), constitutivo del espacio ético, en cuanto que la ética se caracteriza, entre otras cosas, por la voluntad de resolver los conflictos de forma no violenta, sino respetando la libertad del otro, recurriendo, cuando sea necesario, a la discusión racional, al diálogo y a la negociación consensuada. Este principio "sirve de fundamento a lo que se puede calificar de moralidad de autonomía entendida como respeto mutuo", y, en concreto, podría expresarse en la siguiente máxima: "No hagas a otros lo que ellos no se harían a sí mismos, y haz por ellos lo que te has comprometido a hacer" (6).

La asunción de este principio implica que, para resolver disputas morales en una sociedad pluralista, "la autoridad no puede partir ni de argumentos racionales ni de creencias comunes, sino únicamente del acuerdo de los participantes. Consiguientemente, el permiso o el consentimiento constituyen el origen de la autoridad, y el respeto hacia el derecho de los participantes al consentimiento es la condición necesaria para la posibilidad de una comunidad moral" (7).

El principio de autonomía hace posible una comunidad moral, es decir, una comunidad que comparte una concepción homogénea de la vida buena y una jerarquía de valores y fines a perseguir. Tal comunidad solo se constituye y puede existir por la adhesión libre de los individuos. En sí mismo este principio es un tanto formal y vacío --exactamente como el imperativo categórico kantiano fundado precisamente en la autonomía de la persona: "obra de tal forma que trates siempre a la humanidad, tanto en tu persona como en la persona de los demás, siempre como un fin y nunca exclusivamente como un medio"-- en cuanto que no tiene ningún contenido concreto de orden deontológico, axiológico, de normas o valores específicos. 
La única exigencia concreta es que ningún miembro de la comunidad, ni ninguna comunidad moral en relación a otras comunidades, contravenga la regla del respeto a la libertad de los otros. La aparente inspiración kantiana de este principio hace que algunos autores lo presenten como el principio trascendental de la bioética, como su condición de posibilidad y validez (8). El principio protege la libertad personal y solo admite el recurso --legítimo-- a la violencia "cuando una persona o una comunidad moral debe defenderse contra la agresión o la intolerancia de otra persona o colectividad que quisiera, por ejemplo, imponer sus valores y sus fines particulares" (9).

Obviamente sería deseable que en la elaboración y concreción de un programa moral común --por mínimo que fuese-- la razón o el discurso racional jugasen un papel importante. Pero, en general, los teóricos de la bioética no parecen hacerse demasiadas ilusiones en cuanto a la capacidad de la razón humana para fundamentar normas y valores comunes. De ahí que lo determinante en último término no sería la argumentación racional, sino el acuerdo libremente consentido, esté o no conforme con lo que alguien considera como el dictamen de la recta razón. Allí donde la argumentación racional no parece llegar a ningún fin, queda el consentimiento libremente acordado.

\section{Aplicaciones de este principio}

La aplicación general de este principio en el campo de la bioética conduce a la regla que estipula que hay que respetar la voluntad o decisión del paciente respecto a la realización u omisión de una determinada terapia $\mathrm{y}$, también, a escoger entre varias alternativas de tratamiento, en el caso de que existan.

Obviamente para que el paciente pueda adoptar una decisión consciente, libre y responsable, en un sentido o en otro, se requiere que previamente se le haya dado una información, por parte del o de los profesionales respectivos, lo más completa y comprensible sobre cual es realmente su situación y las opciones existentes. Es decir, es necesario que el paciente otorgue no cualquier consentimiento, sino un consentimiento informado, para utilizar una expresión consagrada en el campo de la deontología médica desde comienzos del siglo XIX (10). En otras palabras, el principio de autonomía implica que, en el seno de una sociedad secularizada, una persona adulta y consciente, tiene el derecho a decidir sobre su vida y su salud. Un corolario de esto, a modo de ejemplo, sería que una persona deshauciada tendría el derecho, si así lo quiere, al suicidio asistido, es decir, tendría el derecho a que se le suministren los recursos necesarios para abandonar esta vida.

\section{Críticas a este principio}

Obviamente cuando este principio se intenta llevar a la práctica y a sus últimas consecuencias suscita muchas observaciones e interrogantes, algunos de los cuales exponemos a continuación.

La principal observación es que, como punto de partida, hay una diferencia radical en el modo de entender este principio por parte de creyentes y no creyentes. Los primeros, en general, sostienen que solo Dios es dueño y señor de la vida y que los hombres no pueden disponer libremente de ella como tampoco pueden atentar contra su salud, sino que deben, en cuanto sea 
posible, cuidarla y conservarla. En consecuencia, el principio de autonomía de la persona queda bastante relativizado. Los segundos, al no aceptar a priori una instancia sobrehumana, sostendrán lógicamente que el hombre es dueño y señor de sí mismo, que "es la medida de todas las cosas", para repetir la famosa frase de Protágoras, y que puede decidir libremente sobre su vida y sobre lo que le conviene, en tanto se lo permitan las leyes vigentes en la sociedad donde vive y en tanto no atente contra los derechos e intereses de las demás personas. La situación un tanto embarazosa e ineludible la encontramos expresada en forma rotunda en el siguiente texto: "El médico no tiene sobre el paciente sino el poder y los derechos que éste le dé, sea explícita, sea implícita y tácitamente. El paciente, por su parte, no puede conferir más derechos que los que el mismo posee. El punto decisivo en este debate, es la licitud moral del derecho que el paciente tiene de disponer sobre sí mismo" (11). Queda dicho que para el creyente el derecho de disponer de sí mismo es muy limitado, mientras que para el no creyente la situación es distinta.

¿Cómo salir de este dilema? No parece que pueda imponerse una solución unívoca para todas las situaciones, sino que, como se infiere fácilmente de lo que venimos exponiendo, habrá que respetar escrupulosamente la voluntad --la decisión-- del paciente adulto, cualquiera que ella sea. Pero ni aún esta solución será satisfactoria para todos. Habrá personas que eventualmente piensen que la decisión tomada por un enfermo, en principio competente y en su sano juicio, no es la más conveniente objetivamente para su salud y su vida. Una vez más ¿cómo salir de este impasse? El médico ¿habrá de acoplarse a la voluntad del enfermo aunque él --como profesional y lógicamente con conocimientos superiores-- piense que el paciente está equivocado y que lo que éste considera como lo mejor no lo es en realidad? En la solución que normalmente se dan a estos conflictos se perciben diferencias de raíz cultural. En efecto, en los países anglosajones en los últimos años se ha revalorizado el papel del paciente como persona y se ha superado una visión excesivamente paternalista del médico que decidía en forma unilateral e inapelable la terapia a seguir. Dentro de esta nueva perspectiva se tiende a hacer prevalecer la voluntad o autonomía del enfermo sobre los otros factores que también han de tomarse en consideración (como, por ejemplo el principio de beneficencia, del que hablaremos a continuación).

Por el contrario, en los países de cultura latina, el principio de autonomía del enfermo normalmente no se lo interpreta como la última ratio y sin ninguna limitación. En casos extremos se tiende a hacer prevalecer el principio de beneficiencia --el bien objetivo del paciente-- tal como lo ve el profesional médico, sobre el principio de autonomía del paciente. Y se argumenta, dentro de este contexto, que la libertad de las personas no es absoluta. La autonomía de la voluntad es válida dentro de un cierto marco jurídico, pero no puede ser invocada para ir en contra de principios que regulan el orden público. En este sentido, el artículo VI del Código civil francés --y en general los códigos de los países latinos-- hace depender la validez de los contratos de la no-violación de las reglas "que interesan el orden público y las buenas costumbres". Dentro del orden jurídico francés la vida y la salud no son bienes patrimoniales de los que cada ciudadano puede disponer libremente y eventualmente enajenarlos. Es interesante recordar también a este respecto el artículo V del Código civil italiano, según el cual "los actos de disposición del propio cuerpo están prohibidos cuando causan una disminución permanente de la integridad física, o son contrarios al orden público o a las buenas costumbres" (12). 
En conclusión, no puede absolutizarce el principio de autonomía: no hay obligación de respetar las opciones del enfermo cuando estas son claramente contrarias a la práctica profesional o a la deontología del profesional médico.

Existen otras situaciones o casos especialmente conflictivos y polémicos que de alguna manera también parecen poner limitaciones al principio de autonomía. Entre otros los siguientes.

En primer lugar, tenemos el caso del secreto profesional. Si el principio de autonomía del paciente fuera absoluto, el profesional médico nunca podría ni debería revelar lo que ha llegado a su conocimiento a través de su relación con el paciente en el caso de que éste se opusiera a tal revelación. Sin embargo, sabemos que las cosas no son así y que las legislaciones de casi todos los países, con mayor o menor claridad, permiten, e incluso en algunos casos imponen, la revelación del secreto profesional, aún contra la voluntad del enfermo, cuando están de por medio, por ejemplo, la salud o la vida de terceras personas. Así la Suprema Corte de California ha considerado ilícita la conducta de un psiquiatra quien, conociendo que un paciente suyo iba a asesinar a una mujer no lo advirtió a la víctima, para mantener el secreto aún a costa de la vida de la inocente. A partir de esta sentencia se sostiene en ese país que los profesionales en medicina que "saben acerca de la peligrosidad de un paciente respecto de terceras personas identificables tienen el deber de tomar todas las medidas necesarias para proteger a las potenciales víctimas" (13). Esta norma se aplica también a otros supuestos como, por ejemplo al peligro de transmisión de enfermedades contagiosas. Así, las cortes norteamericanas han acogido demandas de cónyuges contagiados por falta del aviso oportuno del médico tratante de la persona infectada. Y como resultado de diversas sentencias judiciales en aquel país se ha llegado a la conclusión siguiente: el profesional médico debe tratar de convencer a los pacientes de alguna enfermedad contagiosa sobre el deber que estos tienen de advertir a sus allegados del peligro que corren de contagiarse, si no se toman las medidas oportunas para evitarlo. Si los pacientes se negasen a cumplir tal deber, el profesional debe denunciar el hecho ante las autoridades de la salud pública. Y en el caso de que éstas tampoco quieran advertir a las terceras personas del peligro que corren, el profesional en medicina tiene la facultad según unos, o el deber según otros, de advertir directamente a los terceros de los peligros eventuales a los que están expuestos. En cualquier caso, es obvio que el principio de autonomía no es absoluto.

Otro caso muy parecido al anterior es el supuesto derecho que tiene el paciente -en virtud del principio de autonomía - a que no se le informe de la enfermedad que padece, si tal es su deseo. También aquí habría que decir que ese derecho a "no - saber" no es absoluto, sino que, cuando están de por medio terceras personas que corren el peligro de contagiarse sino se toma las medidas oportunas, tanto el afectado como sus próximos allegados tienen el derecho y el deber de conocer los peligros a que están expuestos para tomar las debidas cautelas.

Algunos autores observan además que el principio de autonomía no puede ser un principio general de la bioética -que, en cuanto tal, habría que aplicar para resolver los problemas bioéticos - porque precisamente no se pude aplicar a muchas situaciones en que están de por medio la salud o la vida de personas que, por definición, no gozan de autonomía, por ejemplo, niños, deficientes mentales, enfermos terminales con graves carencias psíquicas, etc. Por nuestra parte, no vemos que esta objeción sea realmente grave. Habría que responder sencillamente afirmando que, como efectivamente los seres aludidos no gozan de autonomía 
para decidir por sí mismos, la autonomía para decidir por ellos recae respectivamente en sus padres, tutores, representantes legales, etc. Por lo demás, así se actúa en casos análogos: herencias, contratos de compraventa, etc.

\section{B) El principio de beneficencia}

Este principio de beneficencia (bene-facere o bonum facere, literalmente: obrar bien o hacer el bien) es inherente e inseparable del ethos de la medicina y "obliga al profesional de la salud a poner el máximo empeño en atender al paciente y a hacer cuanto pueda para mejorar la salud, de la forma que aquel considere más adecuada" (14). Escuetamente se podría formular de la manera siguiente: "haz el bien a los demás". En sí mismo este principio no parece tener nada novedoso: enlaza con las promesas del viejo juramento hipocrático, reitera el clásico primer principio de la filosofía moral tradicional: "Hay que hacer el bien y evitar el mal" y confirma la norma básica de la Declaración de Ginebra de la Asociación Médica Mundial de 1949: "La salud de mi paciente será mi primera consideración".

Así pues, este principio parece obvio e incostestable. Sin embargo, a la hora de entenderlo, interpretarlo y llevarlo a la práctica comienzan también las dificultades. Y la primera es la siguiente: ¿Qué se entiende por bien en el contexto de la bioética contemporánea? Y la respuesta es que nadie lo sabe con certeza, o, dicho en forma paradójica, que no hay respuesta. Como señala uno de los autores más connotados, "cuando se analiza el principio de beneficencia, éste aparece fragmentado en toda una serie de sentidos de beneficencia. No existe un sentido secular canónico, único de lo que es hacer el bien, ya que los bienes al alcance de las personas son múltiples y a menudo incompatibles" (15).

Sin embargo puesto que no parece aceptable renunciar a toda posibilidad de conocer y realizar el bien -puesto que en ese caso la vida moral carecería de sentido-- tal principio se suele expresar en forma más concreta y condicionada: "Haz a los demás lo que ellos consideran que es su bien". Sin embargo, dentro de esta formulación no queda asegurado que lo que el paciente considera como bueno para él, lo sea efectivamente. Nada impide, en efecto, que tome como bien objetivo lo que no pasa de ser un interés transitorio o un deseo apremiante en un momento dado.

No obstante, la dificultad principal es de otra índole. ¿Qué ocurre cuando el médico advierte y sabe con certeza - pues para ello es un profesional especializado- que el paciente ha hecho una mala opción y que lo que él considera como bueno en realidad lo va a perjudicar? Nos encontramos en una situación parecida a la que analizábamos anteriormente cuando, en virtud del principio de autonomía sosteníamos que había que respetar la voluntad del paciente, con las salvedades del caso. En el caso presente estamos ciertamente ante una tensión o colisión entre el principio de beneficencia y el de autonomía. ¿Cuál debe prevalecer? En general los autores sostienen abiertamente la primacía del segundo sobre el primero: El principio de autonomía (también llamado de permiso) "es conceptualmente previo al principio de beneficencia". "El principio de permiso siempre desbanca al principio de beneficencia. La obligación de hacer el bien a los demás es un deber fundamental. Sin embargo, esta obligación como tal es abstracta. Solo en contextos concretos se puede determinar el alcance de la misma y la forma de clasificar u ordenar los diversos bienes que tal vez estén en fuego. La obligación 
general de no recurrir a la fuerza sin autoridad posee un carácter más concreto, en el sentido de que se puede descubrir claramente en situaciones particulares sin apelar a otra cosa que a la comprensión del individuo que sería sometido a dicha fuerza. Es suficiente que dicho individuo exprese su rechazo para que de hecho la autoridad del médico deje de afectar a ese paciente" (16).

Queda dicho que según interpretación común el principio de beneficencia estipula que hay que hacer a los demás lo que ellos consideran como bueno para ellos. Así entendido, parece ser una simple variante de la llamada "regla de oro": "Trata a los demás de la misma forma que quisieras que ellos te traten a ti". Pero si lo interpretamos de esta manera, podríamos estar imponiendo a los demás nuestra visión concreta de lo que es el bien o la vida buena (lo que, obviamente, es inadmisible). Y así, la regla de oro podría servir de base para la imposición dogmática y tiránica de determinadas visiones particulares de lo que uno considera que es bueno o que es una vida buena. Para evitar tales eventualidades, habría que reformular el principio de beneficencia en su máxima generalidad: "haz el bien a los demás". Y de nuevo caemos en la dificultad de que cada cual decidirá lo que es bueno según su propio saber y entender. No es fácil evadir esta aporía. En efecto, si finalmente el principio de beneficencia estipula que se acate la voluntad o el deseo del paciente, tal principio viene a ser una reiteración -ociosa-- del principio de autonomía. De este modo el principio de beneficencia queda vacío de contenido y se llega a la paradoja siguiente: Por una parte se nos manda que realicemos el bien del paciente, pero, por otra, nadie parece saber en que consiste ese bien. En realidad, "el concepto de beneficencia presupone el concepto de bien, de modo que no es posible postular un principio renunciando simultáneamente a la noción que le da origen y lo justifica" (17).

Otro crítico argentino, refiriéndose a este principio, tal como lo entiende $H$. T. Engelhardt, a saber, como un principio formal y universal, sin un contenido concreto, hace la siguiente acotación:

"Si hay consenso (acerca de lo que es el bien) no existirán mayores dificultades en la instrumentación del principio de beneficencia, pero si no lo hay (y este es precisamente el caso que cuenta prioritariamente en la noción de ética de Engelhardt, esto es, un modo de resolución pacífico - de controversias), no se advierte cuál puede ser el sentido de dicho principio. En otras palabras, el principio es útil en situaciones donde precisamente la ética entendida a la manera del Engelhardt, no tiene ninguna función" (18). Dicho de otra manera, el principio es válido únicamente para los "amigos morales" es decir, para situaciones en que se comparten el concepto de bien y unos mismos valores morales; pero el problema principal consiste en que una ética secular y posmoderna debe dirigirse y ser válida también para "extraños morales" (es decir, para los que no comparten idénticas normas ni valores) y en este caso no parece haber posibilidad de alcanzar un acuerdo sobre lo que es bueno con base en una argumentación puramente racional. Una vez más, solo queda el acuerdo operativo por vía de consenso. Y este consenso será la fuente exclusiva de determinación axiológica. Por ello los ciudadanos de un estado pluralista deberán renunciar a la posibilidad de utilizar la fuerza estatal contra individuos "culpables" de cometer delitos sin víctimas - aunque ellos los consideren actos inmorales-- es decir, "delitos" en los que todos los implicados - por supuesto adultos-- han decidido libremente participar, como por ejemplo, venta de pornografía, de mariguana, etc.(19).

Alguien podría replicar que, en el contexto en que estamos hablando, el bien para el paciente consiste, sin discusión posible, en salvaguardar su vida y/o recuperar la salud, en la 
medida en que ello sea humanamente posible. En principio no parece que se pueda objetar seriamente a semejante aserto. Pero, a la hora de la verdad, de nuevo se presentan dificultades. La vida -física-- ¿es en verdad el bien supremo? Si así fuera no tendría sentido que millares de mártires -a los que se considera como héroes y santos a imitar-- hayan ofrendado voluntariamente su vida cuando la podían haber conservado simplemente cambiando de ideas o ideales. La expresión "calidad de vida", tan común en la actualidad, indica claramente que el bien de una persona no siempre es necesariamente vivir más tiempo, como sea, y a costa de lo sea. Ciertamente no hay obligación moral de agotar todos los recursos médicos - tecnológicos para alargar por unos días una existencia precaria y dolorosa. La misma idea la expresan otras conocidas expresiones de nuestro tiempo: "obstinación terapéutica" (someter al paciente a una serie de operaciones sin sentido), "tratamiento selectivo", etc.

Como se sabe, esta última expresión -tratamiento selectivo- en el contexto médico significa que a unos pacientes se los tratará y a otros no. Tal praxis puede representar una conducta correcta cuando se toma como criterio la proporción entre el éxito esperado y los costos e inconvenientes de la terapia. Es decir, cuando no hay esperanza de éxito, o es muy escasa, y los costos de la terapia serían muy elevados y desproporcionados con los recursos disponibles, se puede, moralmente, omitir el tratamiento médico, pero hay otras situaciones en que la aplicación de este principio es más polémica y cuestionable. Por ejemplo, en los Estados Unidos es doctrina común en la actualidad, avalada por la Corte Suprema de ese país, que se puede lícitamente omitir una determinada terapia para una enfermedad cuando esta sea padecida por un niño discapacitado y sus padres no quieren que se le aplique la terapia correspondiente, aunque se trate de una anomalía subsanable desde el punto de vista médico, como por ejemplo, el caso de un niño mongólico nacido con atresia de esófago, que le impide alimentarse, y cuya patología puede corregirse mediante la cirugía pertinente (20).

Para terminar este apartado, nos permitimos recordar la doctrina tradicional sobre el principio de beneficencia. El profesional médico tiene la obligación de hacer el bien al paciente (atender al enfermo procurando su salud) cuando se dan las siguientes condiciones:

- El paciente sufre una pérdida o daño grave.

- La actuación del profesional es necesaria para subsanar ese daño.

- Esa actuación no representa un peligro grave para el profesional médico.

- El beneficio recibido por el paciente supera con creces los eventuales perjuicios que pueden originarse en el personal médico.

Un ejemplo concreto de lo expuesto sería el caso de una persona contagiada por el SIDA. El personal médico está obligado a atenderla cuando su salud, tomadas las precauciones debidas, no corra peligro de contagio. En caso contrario, no estaría obligado. Como alguien ha dicho, haciendo referencia a la parábola evangélica del Samaritano, el principio de beneficencia obliga a ser un "mínimo samaritano", pero no a ser el "buen samaritano".

En conclusión, la aplicación del principio de beneficencia es bastante compleja. Hay que sopesar y ponderar los costos-beneficios, lo que no siempre es fácil. Para ello hay que tomar en 
cuenta los valores e intereses de las personas involucradas, las consecuencias previsibles que se seguirán de la realización del acto médico o de su omisión, etc. (21)

\section{C) El principio de no-maleficencia}

Por analogía, o mejor, por contraste con el principio anterior, a continuación vamos a exponer este principio, que algunos subsumen bajo el citado principio de beneficencia.

Es muy conocido el aforismo clásico en el contexto médico, primum non nocere. "Ante todo, no hacer daño". Pues esto es precisamente lo que establece este principio: no hacer o causar mal. Maleficencia proviene de la expresión latina malum facere, literalmente: hacer el mal.

En realidad, tampoco este principio parece ser muy novedoso ni original de la bioética. Es la aplicación, al campo de la medicina, del axioma ético tradicional "hay que evitar el mal", o de los viejos aforismos jurídicos "no se debe dañar a otro" (alterum non laedere), o "no se debe dañar a nadie" (neminen laedere). En sí este principio puede ser aplicado universalmente a cualquier intervención médica, experimentación, etc. Y viene a ser la expresión sintética de una serie de normas: no matar, no atentar contra la integridad personal, no perjudicar la salud, no inducir discapacidades, no incurrir en mal praxis (iatrogenia), etc.

También aquí, sin embargo, se imponen algunas observaciones. El principio se interpreta normalmente en el sentido de que no se puede hacer daño o mal a otro directamente, pero si se permiten o toleran perjuicios indirectos. En realidad cualquier acción quirúrgica infringe algún mal al paciente y puede producir daños colaterales que son inevitables. Lo que requiere o exige este principio es que aquí tambien haya una debida proporción entre los beneficios que se esperan conseguir y los daños o secuelas perjudiciales que tambien se seguirán como resultado, pongamos por caso, de una intervención quirúrgica o de una medicación. Obviamente los beneficios deben ser superiores a los daños para que la acción sea lícita moralmente. En otras palabras, el principio de no-maleficencia exige al personal médico que se abstenga de proponer tratamientos que, en su opinión, resulten perjudiciales o causen daño al paciente, a menos que esto quede ampliamente compensado por los beneficios que se esperan conseguir. A la hora de la verdad, sin embargo, no siempre será fácil ponderar los beneficios y los perjuicios eventuales. En este sentido se ha hablado de la naturaleza trágica de la medicina "que obliga con frecuencia a elegir entre posibilidades alternativas de diferentes formas de sufrimiento y muerte sin conocer con certeza lo que sucederá. Puede suceder muy bien que se haya decidido realizar una intervención quirúrgica con el fin de salvar una vida y que el paciente muera por efecto de la anestesia. Un médico puede prescribir antibióticos a un paciente que le produzcan una reacción alérgica que ponga en peligro su vida. La naturaleza de las decisiones que deben tomar los médicos lleva aparejada la posibilidad de desembocar inexorablemente en resultados penosos indeseados" (22).

Tal vez aquí convenga recordar también que la ética tradicional no suele aceptar el principio que se atribuye a Maquiavelo según el cual "el fin justifica los medios". Un fin bueno, como podría ser la recuperación de la salud, no puede cohonestar una acción mala en sí misma, si es que se puede hablar así. No es lícito quitar un riñón a un pobre niño abandonado para hacer 
un transplante a un millonario enfermo. También aquí, como en política, al decir de A. Camus, son los medios los que justifican el fin, nunca el fin a los medios.

A veces se arguye que se puede causar directamente un daño en aras de promover un bien mayor o el bien común. Tal afirmación no deja de ser cuestionable. Un pensador notable, como Tomás de Aquino, sostenía ciertamente que el bien común está por encima del bien singular de los individuos, pero también estipulaba que "nadie puede dañar a otro injustamente, para promover el bien común" (23).

En definitiva el deber de no hacer el mal, de no dañar es más obligatorio, más claro y más perentorio que el deber de hacer el bien. El daño que se hace directamente a una persona es más condenable, si cabe hablar así, que el no haber promovido positivamente su bien. Por algo decían los antiguos: "Ante todo, no dañar".

\section{D) Principio de justicia}

La justicia, el ideal de justicia, ha sido siempre una de las grandes metas, tal vez la principal, de toda sociedad humana. Aristóteles, tan parco en sus expresiones, al hablar de la justicia se siente poeta y exclama que "ni la estrella de la tarde ni el lucero del alba son tan luminosos como la justicia".

A Simónides, un poeta griego del siglo VI antes de Cristo, se atribuye la siguiente definición de justicia: "dar a cada uno lo suyo". Siglos más tarde, un jurisconsulto romano, Ulpiano, la completó en la forma siguiente: "Justicia es la constante y perpetua voluntad de dar a cada uno lo que le es debido". Posteriormente, en el siglo VI de nuestra era, Justiniano recogió ésta célebre definición en sus Instituciones y desde ahí ha pasado al acerbo jurídico de la cultura occidental hasta convertirse, en la actualidad, en un lugar común. Sin embargo, esta noción de justicia es casi tautológica. En efecto ¿habrá alguien que se oponga a que se le dé a cada uno lo suyo, lo que se le debe? No parece probable. Como alguien ha observado, en un tono un tanto sarcástico, si una cosa es de uno no hace falta dársela sino no quitársela. Pero el problema capital, que esta definición no resuelve, es determinar, precisar qué pertenece, qué se le debe a cada cual y por qué.

En el ámbito de la bioética el principio de justicia tiene que ver, naturalmente, con el tema tan enorme y tan complejo de la distribución de los recursos médicos, cada día más enérgicamente exigidos pero también más costosos y más escasos. El principio, en sí, dice sencillamente que los recursos terapéuticos disponibles se repartan y distribuyan de la forma más justa y equitativa posible. Lo que, a la hora de la verdad, no aclara gran cosa.

En teoría, lo "suyo" lo "debido" a cada paciente sería lo que este necesita para recuperar su salud o para aliviar su sufrimiento. Sin embargo, sabemos que esto no siempre es posible, ya que, desgraciadamente, es muy frecuente que haya una gran diferencia entre los recursos disponibles --siempre escasos-- y los requeridos para atender debidamente las necesidades -cada día más numerosas por simple crecimiento demográfico-- de los pacientes. 
La problemática concreta que se presenta en este campo es muy vasta y, para muchos pacientes, literalmente vital ya que les va la salud y la vida en el modo concreto que se asignen los recursos terapéuticos disponibles. Por ejemplo, habrá que tomar decisiones para asignar equitativamente los recursos públicos disponibles para determinadas enfermedades, determinadas terapias, determinadas regiones del país, determinados hospitales, determinadas edades, etc. ¿Cómo decidir quien o quienes van a ser los beneficiarios de un transplante de riñón o de corazón, de respiradores artificiales, de diálisis, de drogas muy caras, etc.? A menudo hay que optar entre alternativas excluyentes: por ejemplo o más vacunaciones, medicina preventiva y asistencia médica a la infancia, o más recursos para transplantes y tecnologías muy costosas para atender a enfermos terminales de escasa utilidad en relación a los gastos. Nos guste o no se plantea la relación costos-beneficios en sentido estrictamente económico en la atención a los enfermos. Por ejemplo, dado que el tratamiento y cuidados de los pacientes del SIDA generalmente son muy costosos ¿qué proporción de los recursos de un país deben dedicarse a esa finalidad, a costa eventualmente de dejar de atender otros problemas de salud? (Obviamente, si hay recursos abundantes para atender a toda clase de pacientes no hay problema. Pero no suele ser el caso).

Puestos ya en esta tesitura podríamos citar situaciones más difíciles y polémicas. Por ejemplo ¿hasta que punto la seguridad social o sanitaria de un país está obligada o no, y por qué, a suministrar anticonceptivos, atender solicitudes de aborto, realizar cirugías estéticas para fortalecer los pechos caídos o las nalgas flácidas o para rectificar la curvatura de la nariz?.

Como puede verse, en este campo hay más preguntas abiertas que respuestas certeras y uniformes. No obstante para que nuestra exposición no quede en el mero recuento paralizante de las dificultades y de las dudas, nos aventuraremos a ofrecer algunas pistas de solución.

En primer lugar, para resolver en forma consecuente la mayoría de los problemas relativos a la distribución y prioridad de los recursos terapéuticos disponibles en una determinada sociedad, habría que partir de un esclarecimiento previo de la idea o concepto de justicia. En nuestros días, por ejemplo, mientras unos adhieren a la teoría de J. Rawls, para quien la justicia implica proporcionar a todas las personas condiciones materiales de igualdad y oportunidad, otros son partidarios de la doctrina de R. Nozick, para quien la justicia consiste básicamente en no interferir en los derechos de propiedad ajenos, sino más bien en respetar la autonomía y las decisiones libremente asumidas por los propietarios (24). Lógicamente en el primer caso habrá que postular un sistema de salud público o estatal, mientras que en el segundo tendríamos que inclinarnos por un sistema de salud primordialmente privado para que cada quien cuide su salud con base en sus recursos económicos.

En segundo lugar, y dando por un hecho que el concepto tradicional de justicia social y/o justicia distributiva exigen un sistema básico de salud pública, la decisión para repartir los bienes o recursos terapéuticos disponibles debe tomarse con base en los acuerdos temporales y periódicos a que lleguen las autoridades competentes en materia de salud, ya que no se puede establecer de antemano y de una vez y para siempre una lista fija de prioridades. En cualquier caso, habrá que distinguir cuidadosamente entre propiedad privada y pública y no se podrá utilizar a las personas ni sus propiedades, ni sus servicios sin su correspondiente permiso. En concreto, los autores que abordan esta temática suelen sostener que los médicos y otros operadores de asistencia sanitaria no deben tomar ellos mismos las decisiones específicas para 
distribuir los recursos de salud disponibles. Es preferible que esto lo hagan los responsables de los fondos públicos, es decir, los funcionarios designados por los gobiernos para cumplir estas funciones de índole más bien administrativa. Los gerentes y administradores de los hospitales determinarán en casa caso la cantidad del presupuesto del hospital que se asignará a cada servicio, estableciendo las pautas y procedimientos para asignar los recursos a determinados enfermos, etc. La función de los médicos y demás personal sanitario se centrará en asegurar, dentro de lo posible, el mejor tratamiento a los enfermos, aún en el caso de que dicho tratamiento entre en conflicto con las pautas fijadas por la administración. Se piensa que la eventual tensión o conflicto entre, por un lado, la administración hospitalaria, empeñada en conseguir un sistema de salud eficiente, ágil y lo menos costoso posible, y, por otro, el personal sanitario preocupado ante todo por asegurar la mejor asistencia al enfermo concreto, sin reparar demasiado en los costos, y con independencia del sistema, propiciará un cierto equilibrio de fuerzas que garantizará un sistema de salud aceptable (25).

En tercer lugar, en nuestras sociedades actuales, democráticas y neoliberales (regidas en el plano económico por la ley de la oferta y la demanda) parece necesario e imprescindible que haya distintos sistemas y niveles de salud. El Estado debe proporcionar un sistema mínimo y decoroso de salud pública, al que, en principio todos los miembros de la sociedad puedan tener acceso. Este sistema, según estipuló, por ejemplo, la Comisión Presidencial de Estados Unidos, debe asegurar "un cierto nivel de servicios sanitarios a disposición de todos". Es difícil, por no decir imposible, precisar en qué consiste ese nivel decoroso de servicios accesible a todas las personas. Lo decidirán, en parte, el nivel económico y los recursos médico-tecnológicos habituales en determinadas sociedades y épocas. Por supuesto, al margen de este sistema básico de salud, se permite y es deseable que el dinero y la libre elección de ciudadanos acaudalados organicen y creen sistemas y niveles especiales de servicios de salud para las personas pudientes, y, donde uno pueda, eventualmente, hacerse cirugías estéticas periódicas para mantenerse eternamente joven y con la piel del rostro inmarcesible.

Como conclusión de este apartado podemos recapitular:

a) Parece inevitable que en nuestras sociedades modernas y globalizadas se conjuguen, operen y se complementen distintos sistemas de salud, tanto públicos como privados.

b) Igualmente parece estrictamente necesario y de justicia elemental que exista un sistema de salud pública que asegure a todos, independientemente de su status económico, un nivel mínimo pero decoroso de servicios de salud.

c) La desigualdad en la atención de la salud parece ineludible, ya que los ciudadanos tienen recursos económicos muy dispares y a nadie se le puede prohibir que invierta sus propios recursos en los cuidados de su salud.

d) Es necesario reconocer que los recursos de salud siempre serán limitados y, en general, inferiores a las demandas existentes, por lo que no solo es legítimo sino necesario que las autoridades competentes establezcan prioridades en el suministro de los servicios de salud. 
e) En este campo, como en tantos otros, siempre habrá amplios espacios para que, más allá de lo estrictamente debido en justicia, opere lo que tradicionalmente se ha llamado la caridad y la compasión.

\section{E) Otros principios de la bioética}

Los principios fundamentales, y ya clásicos, de la bioética son los cuatro que hemos explicado anteriormente. No obstante, algunos autores enumeran además otros principios, más polémicos y ambiguos, que vienen a ser, en último término, derivaciones del principio de autonomía o de permiso. Entre esos principios cabe citar el de propiedad y el de autoridad política. Daremos una breve explicación de cada uno de ellos.

El principio de propiedad en el campo de la bioética puede formularse así: "Las personas se poseen a sí mismas, poseen lo que hacen, o lo que otras personas poseen y les transfieren; las comunidades son propietarias en la medida en que las personas crean tales comunidades y transfieren fondos a la propiedad colectiva, o en la medida en que los grupos crean riqueza común. Por tanto: entrega a todos aquello a lo que tienen derecho; abstente de coger lo que pertenece a varios o a uno solo" (26).

La introducción de este principio de propiedad es exigida porque el consentimiento o permiso, sobre el que en definitiva se fundamenta una moral profana o secular, solo es posible en aquellos que se poseen a sí mismos. Esta es la primera forma de propiedad y la conditio sine qua non de cualquier acto consensuado en materia biomédica. De este principio se deriva la legitimidad de la compraventa de recursos sanitarios o servicios médicos, tanto por parte de los individuos como de las comunidades, como por ejemplo la compra de un respirador artificial o de la prestación de servicios de un eminente cirujano.

El principio en sí mismo, tal como lo hemos formulado, parece inocuo e intrascendente, pero también aquí, a la hora de entenderlo y de llevarlo a la práctica, surgen diferencias radicales e insalvables.

Así, algunos autores, como el norteamericano Tristram Engelhardt y el filósofo australiano Peter Singer, interpretan este principio radicalizándolo y llevándolo hasta consecuencias inaceptables, pongamos por caso, para un creyente cristiano. Según estos autores la persona humana es propietaria absoluta de su vida y de su cuerpo por lo que puede disponer libremente de ellos. El citado filósofo texano-norteamericano T. Engelhardt es categórico a este respecto: "Los niños y los meros organismos biológicos humanos son propiedad de las personas que los producen" (27). Según este autor, pues, y según la moral que él propugna, no solo poseemos un derecho de propiedad sobre nuestro cuerpo, sino también sobre los embriones, fetos y bebés que producimos. Tal derecho de propiedad cesa en el momento en que los fetos y los bebés toman conciencia de sí mismos convirtiéndose en personas (28). Estas teorías las fundamentan ambos autores en la tesis defendida abierta y reiteradamente por ellos según la cual los fetos y los bebés son seres humanos, pero no son personas (29). Sobre esta tesis tan polémica tendremos ocasión de volver y de discutirla en el capítulo siguiente. 
En general, las conclusiones anteriores son inaceptables en la cultura occidental tradicional (al menos en la europea) y, en particular chocan frontalmente con la fe cristiana ortodoxa, según la cual, como ya se apuntó anteriormente, el hombre no es dueño soberano de su vida y de su cuerpo, sino un mero usufructuario. Por lo demás, los autores citados son concientes que las tesis que propugnan resultan escandalosas dentro de la tradición cultural de Occidente, pero, según ellos, serían simplemente aplicaciones concretas de una moral laica y profana contrapuesta a una moral basada en creencias judeo-cristianas (30). A pesar de todo, las diferencias en el modo de entender el "principio de propiedad" difícilmente serán superables, ya que en el modelo anglosajón el hombre tiene un derecho de propiedad sobre su cuerpo, mientras que en general en el mundo latino es solo un usufructuario.

Por lo que respecta al principio de autoridad política, estrechamente vinculado con los de autonomía y propiedad, su función es la de definir la autoridad legítima del Estado en una sociedad moderna, secular y pluralista. Pues bien, tal autoridad deriva única y exclusivamente del permiso y del consentimiento de los ciudadanos: "La autoridad política, moralmente justificada, se deriva del consentimiento otorgado por los gobernados, y no de un criterio acerca de lo que constituye la vida buena, incluída la obligación de beneficencia, ya que el significado de este criterio y de esa obligación se elabora por medio del mutuo acuerdo" (31).

En virtud de este principio la autoridad de los gobiernos es sospechosa de abuso, y por consiguiente, de ilegitimidad, por lo menos en los siguientes casos:

a) Cuando se restringe la posibilidad de elección de los individuos libres sin su consentimiento (por ejemplo, intentando prohibir a los adultos la venta de material pornográfico o de un seguro médico privado).

b) Cuando, en general, se regula el libre intercambio de bienes y servicios más allá de la protección contra el fraude, la coerción o la infracción de contratos.

Finalmente, otros autores añaden a los principios reseñados, los siguientes: el principio eminente del respeto a la vida y los principios subalternos o derivados de totalidad, socialidad, subsidiaridad, libertad y responsabilidad. En el fondo creemos que se trata más que todo de una cuestión terminológica, es decir, de cómo se entienden los conceptos o expresiones citadas. El también llamado principio de economía del filósofo medieval G. de Ockham dice que "no hay que multiplicar los entes sin necesidad". Aplicando esta máxima a nuestro caso, podemos ahorrarnos la explicación detallada de los principios últimamente mencionados ya que, como en parte lo reconocen esos mismos autores, los principios de respeto, libertad y responsabilidad quedarían comprendidos e implicados en el principio de autonomía; el principio de totalidad está implícito en el de beneficencia; y los principios de socialidad y subsidiaridad en el principio de justicia (32). Por tanto, renunciamos a explicarlos en detalle, ya que, inevitablemente, incurriríamos en reiteraciones inútiles y ociosas.

Para concluir este capítulo queremos insistir en que la puesta en práctica de los principios clásicos de la bioética con no escasa frecuencia no estará exenta de dificultades. A veces habrá una cierta tensión o colisión entre algunos principios (por ejemplo entre el de autonomía y el de beneficencia). Las circunstancias concretas, la tradición cultural, el buen sentido y la prudencia (33) decidirán cual principio debe prevalecer. En general, los autores de la bioética 
(especialmente los anglosajones) suelen dar preeminencia al principio de autonomía, pero no siempre tendrá que ser así necesariamente.

\section{NOTAS Y REFERENCIAS}

1) W. T. Reich, Introduction, Encyclopedia of Biothics, I, New York, 1978, p.XIX.

2) En el campo jurídico lo que podríamos considerar como un análogo a una ética universal sería precisamente la "Declaración universal de los derechos humanos" proclamada por la ONU en 1948. Por supuesto no han faltado críticos que, desde otras latitudes, con mayor o menor razón, han acotado que esa supuesta declaración universal es, en realidad, la concepción occidental o, incluso, la concepción burguesa de los derechos humanos. Valga también la pena señalar que, en estos tiempos de globalización o mundialización, en el campo de la ética se han elaborado también tratados de ética con vocación de universalidad. Entre los intentos más conocidos tenemos el titulado Proyecto de una ética mundial del famoso teólogo-filósofo alemán Hans Küng (Editorial Trotta, Madrid, 1992).

3) M. Vidal, Bioética. Estudios de bioética racional. 2da ed. Madrid: Tecnos, 1994, p.19.

4) G. Hottois, El paradigma bioético: una ética para la tecnociencia. Barcelona: Anthropos, 1991, p.179.

5) Nos referimos concretamente a uno de los autores más famosos en el campo de la bioética, especialmente en el mundo anglosajón, a saber, H. Tristran Engelhartd en su obra ya clásica Los fundamentos de la bioética. Traducción de I. Arias, G. Hernández y O. Domínguez, Paidós, Barcelona, 1995, 545 pp. La primera edición original fue publicada por Oxford University Press en 1986, y la segunda, bastante ampliada respecto a la primera pero idéntica en cuanto al fondo de sus doctrinas, en 1995. La traducción española está hecha sobre la segunda edición inglesa y a ella remiten los textos que citaremos con alguna frecuencia.

6) T. Engelhardt, Obra citada, p.138.

7) Ibídem.

8) Ver, entre otros, G. Hottois, EL paradigma bioético, p.182.

9) Ibídem.

10) Ver Camilo Tale, "Examen de los principios de la bioética contemporánea predominante", en Sapientia, Buenos Aires, Vol. LIII, fasc.204, 1998, p.447.

11) Pío XII, Alocución del 13-9-1952. Citado por Camilo Tale, Art. cit., p.448. 
12) Ver Roberto Andorno, Bioética y dignidad de la persona. Madrid: Tecnos, 1998, pp. 44-45.

13) Ver Camilo Tale, Examen de los principios ... p.449.

14) Javier Gafo, 10 Palabras clave en bioética. Estella (España): Edit. Verbo Divino, 1993, p.18.

15) H. T. Engelhardt, Los fundamentos de la bioética, p.141.

16) Obra citada, pp.139 y 144.

17) Camilo Tale, Examen de los principios de la bioética ..., p.442.

18) Jorge Martínez Barrera, "Los fundamentos de la bioética de H. Tristram Engelhardt", en Sapientia, (Buenos Aires), vol. LII, fasc. 201, 1997, p.111.

19) Ver J. Martínez Barrera, Art.cit., p.112.

20) Ver Camilo Tale, Examen de los principios de la bioética..., p.444.

21) Ver J. Gafo, 10 Palabras clave en bioética, p.19.

22) H. T. Engelhardt, Los fundamentos de la bioética, pp.149-150.

23) "Nullus autem debet nocere alicui injuste, ut bonum commune promoveat": Suma Teológica, II-II, q.68, art. 3c.

24) Ver las respectivas obras, ya clásicas, de estos dos autores: John Rawls, Una teoría de la justicia. México: Fondo Cultura Económica, 1979; y Robert Nozick, Anarquía, Estado y Utopía. México: Fondo Cultura Económica, 1988.

25) Ver H.T. Engelhardt, Obra citada, p.420.

26) Ibídem, p.186.

27) Ibídem, p.184.

28) Ibídem, pp. 178 y 277-278.

29) Ibídem, pp. 257-258 y 275-278; Peter Singer, Ética Práctica, 2da edic. Barcelona: Ariel, 1988, pp.99-100 y 121-160.

30) Ver H.T.Engelhardt, Obra citada, p.279.

31) Ibídem, p.201. 
32) Ver, por ejemplo, Roberto Andorno, Bioética y dignidad humana, pp.34-45.

33) La prudencia - la famosa phronesis de que habla Aristóteles-- es definida por él como "una disposición práctica acompañada de una regla verdadera concerniente a lo que es bueno y malo para el hombre" (Ética a Nicómaco, VI, 5, 1140 b). Además, según Aristóteles, la prudencia recae sobre lo contingente, es decir sobre lo que puede ser y no ser. 